\title{
"BCN Comparteix El Menjar" [Barcelona Shares Its Food], A Food Waste Reduction Model of HORECA Sector in Barcelona
}

\author{
Vidal Ibáñez M1, Homs Bassedas $C^{1 *}$, Vidal Monès B ${ }^{1}$, Milà-Villarroel $R^{1,2}$, Serra-Majem, LL ${ }^{1,3}$ \\ ${ }^{1}$ ONG Nutrición Sin Fronteras \\ ${ }^{2}$ Universitat de Vic-Universitat Central de Catalunya (UVic-UCC) \\ ${ }^{3}$ Instituto de investigación biomédica y de ciencias de la salud, Universidad de Las Palmas de Gran Canaria
}

*Corresponding author: Homs Bassedas C, ONG Nutrició Sense Fronteres (NSF), C/ Rocafort 242, bis, $3^{\text {rd }}$ floor 08029, Barcelona, E-mail: clara@nutricionsinfronteras.org http://www.nutricionsinfronteras.org/; merce@nutricionsinfronteras.org berta@nutricionsinfornteras.org; raimon@nutricionsinfronteras.org

\begin{abstract}
Working against food waste is key to reduce hunger and to improve food sustainability. One third of the edible parts of the foods produced for human consumption are wasted, what represents 1.300 millions of tonnes per year worldwide. From those, 11 millions of tones come from food services, such as hotels, restaurants and caterings, sector in Europe. At the same time, the current economic crisis has worsened the living conditions of countries like Spain; increasing the amount of people at risk of suffering from food insecurity. For instance, $29,2 \%$ of Spanish population (13.4 millions of people) was living at risk of poverty or social exclusion in 2015. Since 2012, the NGO Nutrició Sense Fronteres (NSF) is working in an innovative project named "BCN Comparteix el menjar" [Barcelona Shares its Food] aiming to reduce food waste among the HORECA (Hotels, Restaurants and Caterings) sector in Barcelona. This article describes the methodology of a food waste recovery and distribution system, together with its main protocol steps and its collaborators, which are20 4 and 5 star hotels, 8 caterings and 10 food companies. Results from this project show that more than 80524 $\mathrm{kg}$ of food and 47519 litres of water have been recovered and distributed from January 2013 until December 2015. All the recovered food and water were distributed among 17 social centres, which together benefit 73.669 people and 15.862 families living at risk of poverty and social exclusion.
\end{abstract}

Received date: July 26, 2016

Accepted date: September 30, 2016

Published date: October 04, 2016

Citation: Clara, H.S., et al. "BCN Comparteix El Menjar" [Barcelona Shares Its Food], A Food Waste Reduction Model of HORECA Sector in Barcelona. (2016) J Environ Health Sci 2(3): 1- 4.

DOI: $10.15436 / 2378-6841.16 .1023$

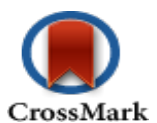

\section{Introduction}

Food losses refer to the decrease in edible food mass throughout the part of the supply chain that specifically leads to edible food for human consumption. Food losses take place at production, port-harvest and processing stages in food supply chain. Food losses occurring at the end of the food chain (retail and final consumption) are rather called "food waste", which related to retailers' and consumers' behaviour (FAO, 2011). Working against food losses is essential to reduce hunger and to improve food sustainability among the most vulnerable populations. Food losses lead to important economic and environmental consequences.
Some of the most relevant data show that about one third of edible foods for human consumption are wasted, representing 1.300 millions of tonnes per year worldwide. From these, 88 million tonnes of food being in good conditions come from the European Union (EU) (FAO, 2012). Household (47 million tones \pm 4 million tons) and processing (17 million tones \pm 13 million tons) are the sectors with the biggest contribution to food waste. These two sectors account for the $72 \%$ of EU food waste. Of the remaining 28 percent of food waste 11 million tons $(12 \%)$ comes from food service, 9 million tons $(10 \%)$ comes from primary production and 5 million tons $(5 \%)$ comes from wholesale and retail. The mean food waste per inhabitant is of $173 \mathrm{~kg}$ in EU (Stenmarck \& Jensen, 2016). 
Spain, with 7.7 million tonnes per year, is the seventh country with the highest food waste rate in EU. The mean food waste among Spanish households (2.7 people per household) is 1.3 kilograms per week and 76 kilograms per year, representing half kilogram of food waste per person per week. Hence, more than 1.5 million tonnes of food are wasted among all the Spanish households (Ministerio de Agricultura Alimentación y Medio Ambiente, 2012). In Catalonia, 262.00 tonnes of food are wasted yearly, representing 35 kilograms of food per person per year (ARC i UAB, 2012).

According to the Save Food worldwide initiative, about food losses and food waste, action should be taken based in the following bases: increase the collaboration and coordination among worldwide initiatives; increase the amount of awareness programmes regarding impact and possible solutions; invest in research on policies, strategies and programmes; and support projects that implement food waste reduction strategies. Furthermore, public administrations should be involved in these actions (Save Food Initiative, 2016).

In order to improve this situation, the aim of " $\mathrm{BCN}$ Comparteix el menjar" project is to reduce food waste among HORECA sector in Barcelona.

\section{Methodology}

\section{Design and participants}

This is a longitudinal study initiated in September 2012, still working nowadays.

The main participants of the project were the food donor centres. They were composed by 204 and 5 star hotels, 8 caterings and 10 food companies, which had food surplus.

Project participants were eligible if they met the following criteria: located in Barcelona or Area Metropolitana de Barcelona; having surplus of food cooked but not served which they are willing to donate; having the facilities, equipment and utensils appropriated to carryout restoration activities; having enough kitchen staff who respects good hygiene practices and food manipulation and can work for the project; having enough storage capacity in freezers $\left(-18^{\circ} \mathrm{C}\right)$.

Once the food donor centres eligible for the project accept to participate, a collaboration agreement between the donor centre and NSF was signed. Within this agreement, it became official that NSF took the responsibility of the state and quality of the foods, from the donation until the distribution moment.

\section{Food storage protocol}

In the food donor centres, the food surplus was collected in plastic containers of 1.5 litres capacity purchased by the donor centre. They must allow being frozen and later on to defreeze in a microwave. There were specific kitchen workers trained by NSF team, who transferred the surplus food in the container. Then, they attached a project sticker per container with the following information: type of food; amount of food $(\mathrm{kg})$; temperature of the food during the donation; possible allergens. Once tagged, the food was kept in a freezer at $-18^{\circ} \mathrm{C}$. When the donor centre reached their maximum storage capacity for the project, they contacted the logistics responsible of the NGO to collect the food.

\section{Data collection}

All the methods used in this study were based on an internal protocol created by NSF, which involved: temperature monitoring during the transport, traceability and quality control of the foods.

The surplus of prepared frozen foods was collected from the donor centres participating in the project, once they reach them maximum storage capacity. The logistics responsible of NSF, organized the collection of food from the different donor centres every week. Depending on the food donations, the most efficient routes were established daily to collect and distribute all the food within the shortest period of time. Transportation of food was performed on an isothermal van. This way, the cold chain was kept during all the process (recuperation, storage, collection, transport and distribution) to assure the best food quality and conditions. All the food collected was distributed within the same day. Regarding the traceability of the food, two delivery notes were filled in: one during the food collection and the other one during food distribution. Both delivery notes contained information on: date of collection or distribution respectively; name of the donor centre; name of the distribution centre; temperature of the foods during collection or distribution respectively; list of the foods donated or distributed respectively with their corresponding amounts (kilograms (kg)). NSF kept a copy of each delivery note. Information contained in the delivery notes was entered in a database. It allowed knowing the nutritional profile and amounts of food in $\mathrm{kg}$ and rations collected and distributed. Within the database, the foods were classified according to: food donor centres; food distribution centres; and 6 food groups designed by NSF according to its nutritional characteristics (fruits; vegetables; dairy products; meal containing warm meal, fish, eggs or legumes; warm meal containing pasta, rice, potatoes or bread; biscuits and pastry; water). Moreover, a laboratory collaborating in the project weekly performed quality controls of donated foods from 3 different donor centres. This way, good quality and management of the foods during the transportation was assured. In case the analyses detected something wrong with one of the foods, both the donor and the distribution centre would have been informed.

\section{Data analysis}

Means and total $\mathrm{Kg}$ of food were used to provide an indication of average week food recovered. ANOVA test were used to compare food groups according by year and type of food donor. A 0.05 level of significance was considered. The statistical software package IBM SPSS Statistics version $21 \bullet 0$ was used for data analysis.

\section{Results}

"BCN Comparteix el menjar" project recovered and distributed a total of $80524 \mathrm{~kg}$ of food and 47519 litres of water from January 2013 until December 2015. These were delivered among 17 social centres that benefited people living at risk of poverty and social exclusion. From the total amount of food and water mentioned, $31128 \mathrm{~kg}$ of food and 2879 litres of water were recovered and distributed during 2013, $25691 \mathrm{~kg}$ of food and 28007 litres of water in 2014, and $23705 \mathrm{~kg}$ of food and 16633 litres of water in 2015.

During 2013, 2014 and 2015, median weekly recovered 
amounts per food group were: $497.93 \mathrm{~kg}$ of cereals/legumes/potatoes; $331.38 \mathrm{~kg} /$ week of fruits; $327.98 \mathrm{~kg} /$ week of sandwiches; $288.68 \mathrm{~kg} /$ week of pastry; $284.8 \mathrm{~kg} /$ week of meat/eggs; 162.45 $\mathrm{kg} /$ week of vegetables; $62.89 \mathrm{~kg} /$ week of fish and $57 \mathrm{~kg} /$ week of dairy products.

Regarding the amount of food groups recovered per year, it was shown that significantly more fruits were recovered in 2014, compared to 2013 and 2015 (5150 kg vs. $3850 \mathrm{~kg}$ and $4255 \mathrm{~kg} ; \mathrm{p}=0.07)$. The same was observed for vegetables: 3736 $\mathrm{kg}$ in 2014; $958 \mathrm{~kg}$ in 2013 and $1805 \mathrm{~kg}$ in 2014 ( $\mathrm{p}<0.005)$. Regarding meat/eggs, in 2013 the project recovered significantly more meat/eggs (4922 kg), in comparison to $2014(2324 \mathrm{~kg})$ and $2015(4146 \mathrm{~kg})(\mathrm{p}=0.005)$. Also, the amount cereals/legumes/ potatoes recovered in $2013(8349 \mathrm{~kg})$, was significantly higher than in $2014(5894 \mathrm{~kg})$ and $2015(5674 \mathrm{~kg})$; $(\mathrm{p}<0.005)$. No significant differences between the amounts of other food groups recovered per year were observed (Figure 1).

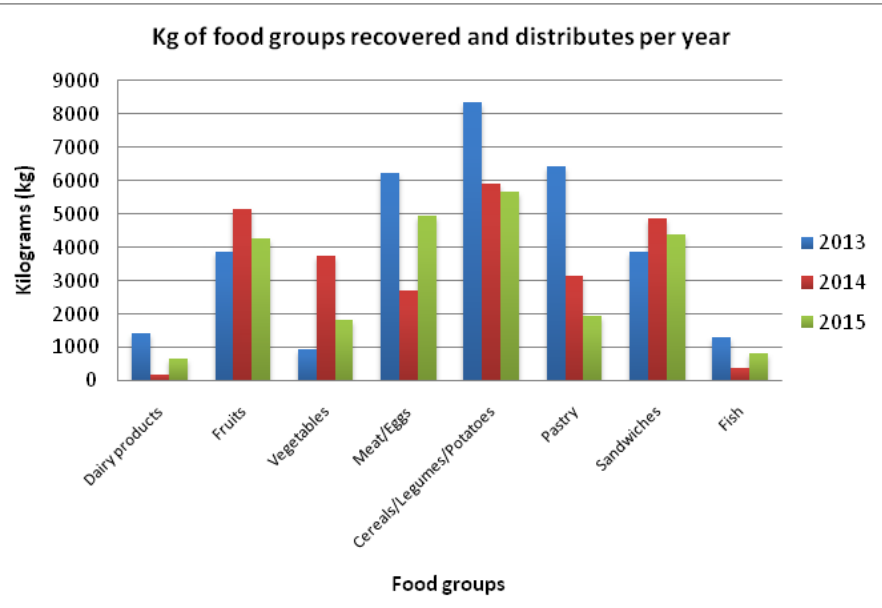

Figure 1: Kilograms of food recovered and distributed according to food groups per year by BCN Comparteix el Menjar.

Comparing the amount of each food groups recovered between donor centre types, it was observed that food companies donated significantly more fruits $(1240 \mathrm{~kg})$ compared to caterings $(1871 \mathrm{~kg})$ and hotels $(1124 \mathrm{~kg}) ;(\mathrm{p}<0.005)$. While for meat/ eggs, hotels donated a significantly higher amount $(8364 \mathrm{~kg})$ in comparison to caterings $(3880 \mathrm{~kg}$ ) and food companies (3052 $\mathrm{kg}) ;(\mathrm{p}<0.005)$. The same was observed with fish: hotels donated $1754 \mathrm{~kg}$; caterings donated $1061 \mathrm{~kg}$; and food companies donated $189 \mathrm{~kg}(\mathrm{p}<0.005)$. Regarding cereals/legumes/potatoes, hotels also donated a significantly higher amount $(14466 \mathrm{~kg})$ compared to caterings (3428 kg) and food companies $(1812 \mathrm{~kg})$; $(\mathrm{p}<0.005)$. While for pastry, caterings donated a significantly higher amount $(13582 \mathrm{~kg})$ compared to hotels $(1853 \mathrm{~kg})$ and food companies $(242 \mathrm{~kg})$. Finally, caterings also donated a significantly higher amount of sandwiches $(14489 \mathrm{~kg})$, compared to food companies $(216 \mathrm{~kg})$ and hotels $(78 \mathrm{~kg}) ;(\mathrm{p}<0.005)$. No significant differences between the amounts of the rest of food groups recovered between food donor centre types.

\section{Discussion}

"BCN Comparteix el menjar" project is an innovative project to reduce food waste among the HORECA sector in Barcelona. There is not previous published literature on similar projects.
"BCN Comparteix el menjar" project has recovered and distributed a total of $80524 \mathrm{~kg}$ of food and 47519 litres of water from January 2013 until December 2015. The amount of food recovered by the project decreased with the years $(31128$ $\mathrm{kg}$ in 2013, $25691 \mathrm{~kg}$ in 2014 and $23705 \mathrm{~kg}$ in 2015). The main reason for the decreased amount of food recovered per year might be that food donors (hotels, food companies and caterings) are every time more aware of their food waste, and its economical costs, so they improved their food waste management to reduce it. For instance, many hotels collaborating in the project removed the buffets for lunch and dinner because of the high amount of food wasted, and changed it to menu. Other food donor centres, have started giving their food surplus to the workers, for lunch and dinner. Therefore, more food donor organizations are needed to increase the amount of food recovered within the project. However, the increasing awareness about food waste is everyday more common, so more hotels and food companies willing to participate in the project. A possible reason why the biggest amount of food recovered in the project were cereals/ legumes/potatoes and fruits, could be due to their higher frequency of consumption and their more economical costs, compared to the other food groups. The following most recovered food groups were sandwich and pastry, which are mostly offered during events and breakfast buffets. These offer bigger amounts of foods, and have a high food waste rate.

Regarding the differences on the amount of food groups donated concerning food donor centre type, hotels donated significantly higher amounts of meat/eggs, fish and cereals/ legumes and potatoes. This might be because these are luxury hotels that offer a high diversity of foods to their clients, and might have food surplus of more expensive, fresh and nutritious kind of foods such as meat and fish. Nevertheless, hotels are the big majority of the food donor centres in the study, fact that might influence the proportions of the food donated in comparison to food companies and caterings. Instead, food companies donate significantly higher amount of foods than hotels and food companies. A reason for it could be the type of company, since one collaborating in the project is specialized in vegetables and fruits. Another reason might be that donated fruits were not frozen. Therefore, it might be a reason for the companies to throw it away rather than storing them to be recovered and distributed by the project. Finally, caterings donate significantly higher amounts of pastry and sandwich. These food groups are common in buffets and events organized by companies in special occasions. Moreover, they are also economical foods that can be well preserved at room temperature, so caterings offer them in higher amounts compared to the main dishes. Therefore, these practices might give room to food surplus.

Finally, the present project presented a high efficiency in recovering food surplus of the HORECA sector in Barcelona. It has recovered and distributed more than 8 tonnes of food that would have been wasted, and has distributed it to 17 social centres benefiting people living at risk of poverty or social exclusion. The capacity of this methodology is very high, taking in to account its simple methodology and few infrastructures and "equipment" needed. Nevertheless, due to the increasing awareness that HORECA sector companies have about food waste, more food donor centres will be needed to collaborate in the project in order to maintain or increase the total amount of food recovered. 


\section{Conclusion}

The project "BCN Comparteix el menjar" is a very innovative and efficient project reducing food waste among the HORECA sector in Barcelona. Awareness against food waste among HORECA sector is increasing in Barcelona, and consequently food waste is being reduced. Therefore, action against food waste should be taken in other sectors of the food chain, such as households and processing, should be taken to reduce and eradicate food waste in Barcelona.

\section{Bibliography}

1. ARC i UAB. Diagnosi del malbaratament alimentari a Catalunya. (2012) Barcelona.

2. FAO. Global food losses and food waste- Extent, causes and prevention. (2011) Rome.

3. FAO. Pérdidas y desperdicio de alimentos en el mundo. (2012)

4. Ministerio de Agricultura Alimentación y Medio Ambiente. Definiciones y cifras: Estrategias más alimentos menos desperdicio. (2012). 5. Save Food Initiative. Save food. (2016)

6. Stenmarck, A., Jensen, C. Estimated of European food waste levels. (2016) Stockholm.
Ommega Online Publishers

Journal Title: Journal of Environment and Health Science (JEHS)

Journal Short Name: J Environ Health Sci
Journal ISSN: 2378-6841

E-mail: environmentalscience@ommegaonline.org

Website: www.ommegaonline.org 